University of Nebraska - Lincoln

DigitalCommons@University of Nebraska - Lincoln

$12-2008$

\title{
Evaluating Vendor-Managed Inventory (VMI) in Non Traditional Environments Using Simulation
}

\author{
Peter Southard \\ University of St. Thomas, St. Paul, MN \\ Scott Swenseth \\ University of Nebraska - Lincoln, sswenseth1@unl.edu
}

Follow this and additional works at: https://digitalcommons.unl.edu/managementfacpub

Part of the Management Sciences and Quantitative Methods Commons

Southard, Peter and Swenseth, Scott, "Evaluating Vendor-Managed Inventory (VMI) in Non Traditional Environments Using Simulation" (2008). Management Department Faculty Publications. 25.

https://digitalcommons.unl.edu/managementfacpub/25

This Article is brought to you for free and open access by the Management Department at DigitalCommons@University of Nebraska - Lincoln. It has been accepted for inclusion in Management Department Faculty Publications by an authorized administrator of DigitalCommons@University of Nebraska - Lincoln. 
Published in International Journal of Production Economics 116:2 (December 2008), pp. 275-287; doi 10.1016/j.ijpe.2008.09.007

Copyright $\odot 2008$ Elsevier B.V. Used by permission.

http://www.sciencedirect.com/science/journal/09255273

Submitted March 28, 2007; accepted September 6, 2008; published online October 1, 2008.

\title{
Evaluating vendor-managed inventory (VMI) in non-traditional environments using simulation
}

\author{
Peter B. Southard \\ Opus College of Business, University of St. Thomas, St. Paul, MN 55105, USA \\ (Corresponding author - tel 651 962-5082, email sout8188@stthomas.edu ) \\ Scott R. Swenseth \\ University of Nebraska - Lincoln, Lincoln, NE 68588-0491, USA \\ (tel 402 472-3308, email sswenseth@unl.edu )
}

\begin{abstract}
This study provided empirical evidence that sufficient economic benefits could be achieved with the use of a technology-enabled vendor-managed inventory (VMI) system in a unique chain such that a firm could justify spending the money necessary to create the infrastructure to support it. The models, while based on a specific type of business, were still generic enough that the results could be generalized to many types of highly distributed, variable demand delivery systems. The study compared the costs of inventory systems used in practice by rural farm cooperatives to possible technology-enabled systems. Fuel delivery data from two agricultural cooperatives in Nebraska provided the basis for this study. The data were used to construct demand distribution for discrete event simulation models of conventional cooperative fuel delivery systems. The results generated from this base model were compared to the operating costs of a technology-enabled system under a variety of VMI implementation alternatives. Performance was measured in inventory costs, delivery costs and stockouts. The study found that VMI alternatives outperformed traditional delivery methods and that the use of such technology could be economically justified in many logistics problems dealing with variable demand patterns through the cost savings created.
\end{abstract}

Keywords: vendor-managed inventory, simulation, supply chain management

\section{Introduction}

Advances in information technology have increased both the scope and intensity of competition between organizations. The challenge of obtaining a long-term competitive advantage in this highly competitive marketplace has depended on excelling at the competitive dimensions of cost, flexibility and customer response (Bechtel and Jayaram, 1997). Improved communication has facilitated the creation of these competitive advantages for the entire supply chain.

Theoretical and empirical evidence support the claims of improved competitive advantages throughout the supply chain, but the empirical evidence has been limited to well-established stable demand supply chains. The basic question this research sought to answer was whether the same could be claimed in less stable environments. Thus, the purpose of this study was to examine the performance of a technology-enabled vendor-managed inventory (VMI) relationship in the multiple-destination, multiple-decision, high-demand-variability environment of the supply chain of agricultural service firms when compared to conventional "manual" processes.

The study focused on the relationship between the distributor and the individual business units supplied by the distributor. The study developed a base model of a farm cooperative fuel delivery system (the Next Closest model), using simulation and actual farm fuel delivery data, which represented multiple existing cooperative delivery systems. A second base model using First Come, 
First Served was also constructed. This model is used to create a secondary reference point and to aid in model validation. The goal was to ensure that the model behaved as expected when converting from the Next Closest model currently in practice to the First Come, First Served model that had already been eliminated due to route inefficiencies. Alternative systems using VMI were then developed and compared with the base models using statistical analysis.

\subsection{Farm fuel delivery environment}

Agricultural cooperative's farm fuel delivery systems were ideal for this study due to the volatility of demand patterns, long-established supply relationships and the oligopoly nature of the relationship between sellers and buyers. This oligopoly relationship leads to an extremely competitive environment within a manageable modeling environment. To this extent, margins are low, leading to a strong emphasis on reduced costs; prices are competitive, leading to a strong need to focus on other competitive factors; and high service levels are required.

This research was conducted in two stages. The stages were defined by Order Qualifiers and Order Winners. In the first stage, each model was compared to the base model to determine whether it qualified for further consideration. In the second stage, the qualifying models were compared to the base model to determine the extent to which each outperformed the base model on the Order Winning criteria.

The base model in this study, referred to as the Next Closest model, was designed to replicate the decision logic applied in the current farm fuel delivery process. In this model, orders are accumulated through time until the driver is ready to load and begin delivery. The driver then identifies the location nearest the base and begins the delivery process. Once the first delivery is made, the driver identifies the location nearest the current location. This process continues until all outstanding deliveries have been made. The observed effect of this base model is increasing inefficiency throughout the route. Figure 1 demonstrates the flow structure of the Next Closest model.

First Come, First Served is included as an alternate base model. Here, deliveries are made in the sequence orders are received, regardless of the inefficiencies in the delivery process. While impractical in this environment, it is provided as a means of comparison to another model commonly implemented in service environments.

\subsection{Vendor-managed inventory models}

Three alternative VMI models are identified for consideration. Fixed Interval (with two alternative delivery cycles) is a route-based system in which drivers cycle through routes in a "milk run" fashion, delivering to each location along the route regardless of current consumption rates. Keep Full is a fixed route model in which initial orders are placed, but once one order is placed from a location on a route, the driver completes deliveries to all locations on the route. The potential benefit of the Keep Full model is that deliveries are bypassed on routes where customers have insufficient demands. Monitored Fuel Level (with three trigger levels) operates similar to the Keep Full model, but deliveries are only made if fuel consumption has depleted inventory to an established trigger point.

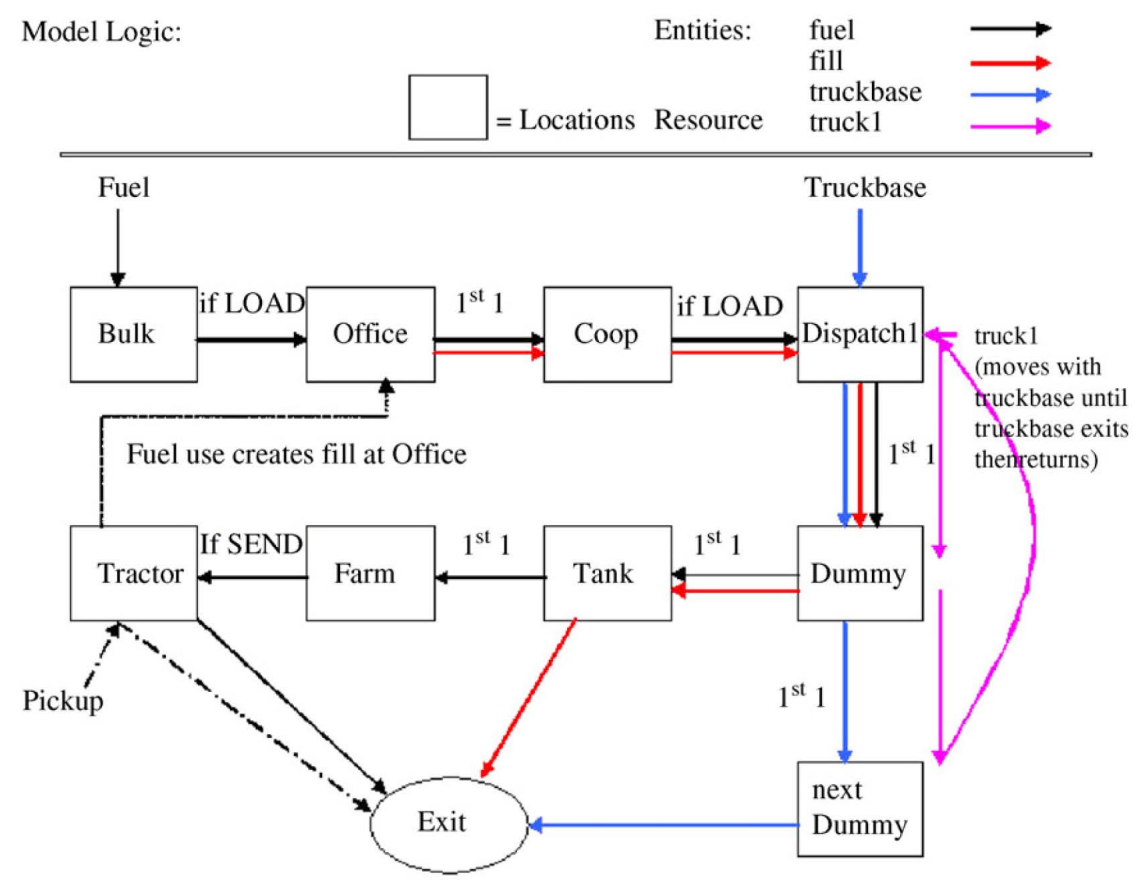

Figure 1. Base model schematic. 


\section{Literature review}

\subsection{Vendor-managed inventory models}

VMI has been described as an inventory and supply chain management tool in which the supplier has taken the responsibility for making decisions as to the timing and amounts of inventory replenishment. This tool has also been called a continuous replenishment process, continual replenishment or auto/automatic replenishment. Wal-Mart, K-Mart and Proctor \& Gamble popularized VMI in the 1980s (Blatherwick, 1998; Waller et al., 1999). While VMI has been widely recognized by industry leaders, such as Wal-Mart and the Campbell Soup Company, for creating a competitive advantage, it received little attention in current operations literature until recently.

The advantages of using VMI to the downstream member, usually a large retailer, have been well documented (see e.g., Cachon and Fisher, 1997; Clark and Hammond, 1997; Fraza, 1998; Waller et al., 1999). Waller et al. (1999) noted that the main advantages of VMI were reduced costs and increased customer service levels to one or both of the participating members. Cetinkaya and Lee (2000) found that VMI greatly reduced inventory-carrying costs and stockout problems while, at the same time, it offered the ability to synchronize both inventory and transportation decisions. Fox (1996) noted that VMI's advantages included improved customer service, reduced demand uncertainty, reduced inventory requirements and reduced costs based on a case study at Johnson \& Johnson, which initiated a continuous replenishment program in 1991. He stated that Black \& Decker decreased returned goods from one of its retail customers from $\$ 1$ million to $\$ 75,000$ and that Schering-Plough increased service levels to $99 \%$ while it decreased inventory levels by $25 \%$ as a result of VMI implementations. Williams (2000) reiterated these same benefits and added the benefits of improved customer retention and reduced reliance on forecasting. Spethman (1993) reported Quaker Oats recent initiation of a VMI system with downstream retailer grocers for inventory control. Andersen Consulting (now Accenture) estimated that organizations could realize capital reductions in inventory and receivables of $20-30 \%$ through the use of VMI, based on results that they had observed in the chemical industry (Challener, 2000).

While some authors felt that the downstream member benefited at the expense of the upstream one, Latamore (1999), Challener (2000), Jain (1994) and Clark and Hammond (1997) believed that the upstream member benefited as well. With reduced stockouts, suppliers not only saved customer goodwill but they also increased sales along with receiving more information on the customer's demand patterns that aided the supplier in better planning their own inventories. The ability to better plan inventories and deliveries was often cited as a major advantage to the upstream member of using VMI.

Chaouch (2001) developed an analytical model to calculate inventory levels and delivery rates to minimize costs for small suppliers forced to use VMI by larger customers. That model used very specific assumptions regarding the variability of demand. One important finding of the study, however, was that reducing variability in the amount and timing of demand increased the benefits of lowered inventory. Blatherwick (1998) noted that VMI was an excellent tool when the downstream supply chain members ordering policies were less sophisticated and erratic or when the distributor was selling to a large number of buyers with erratic buying patterns, similar to the problem domain of this study.

In all documented cases of organizations using VMI, there was some connection between the members in order to facilitate the exchange of information on inventory levels, product usage and re-supply issues. Generally this connection was provided with electronic data interchange (EDI) (Emigh, 1999). Haavik (2000) stated that using electronic data exchange tools were needed to realize the full benefits of VMI. Lawrence and Vokurka (1999) and Challener (2000), however, described situations where the exchange was a manual process. In these cases, a representative from the upstream member physically monitored the inventory level. In addition to EDI, Challener also described two other electronic methods used in the chemical industry: (1) radio frequency sensors on packaging and (2) telemetry that sent signals from a tank-mounted sensor.

Achabal et al. (2000) present a case study in which they describe a decision support system (DSS) developed in the apparel industry for a VMI system resulting in improved customer service levels and faster inventory turns. The system consisted of two major components, a forecasting module (including a promotional response model) and an inventory decision module along with a parameter estimation and updating component. The study showed that the DSS provided quantifiable financial benefits to the company.

De Toni and Zamolo (2005) offered a case study to demonstrate the benefits of VMI in an Italian appliance company. It described the implementation of VMI by Electrolux in Italy and the improvements over the old system that it created.

Holweg et al. (2005) used case studies to identify weaknesses in past VMI implementations concluding that effectiveness is dependent on the integration of internal and external operations as well as how well the VMI strategy fits the supply chain and its configuration. They also provided a theoretical classification of VMI systems based on the degree of planning collaboration and the degree of inventory collaboration.

Dorling et al. (2006) looked at VMI in oligopolies and its determinants of success. Using literature reviews and case studies, they proposed seven theoretical factors, or steps, impacting success in the food chain oligopoly of New Zealand: industry structure, rivalry within the industry, buyer's power, industry profitability, ability to develop long-term relationships, supply chain technology and adoption of SCM best practices. 
While most VMI studies focus on a dyadic relationship, Danese (2006) investigated how to extend that research both upstream and downstream to incorporate the entire supply network. Using a single case study, the article discusses the need for information technology to extend information sharing, and therefore VMI, beyond the dyad normally studied.

Vigtil (2007) described a set of five case studies that indicated sales forecasts and inventory positions were the most valuable information provided to suppliers by the buyers in a VMI relationship.

Analyzing determinants of VMI success through a survey of 94 employees of 25 companies, Kuk (2004) found that VMI benefited smaller organizations more than larger ones. He also noted that employee involvement and integrated logistics facilitated increased benefits from VMI.

Pohlen and Goldsby (2003) made a distinction between supplier-managed inventory (SMI) and VMI proposing a theoretical framework of different approaches be used for each. Their distinction lay in which link of the supply chain was being analyzed with the supplier to manufacturer being SMI while manufacturer (or distributor) to retailer being VMI. They used economic value analysis as the underlying method for analysis within the framework.

There is a definite need for additional research in this particular area. Inventory has been considered one of the major drivers of the supply chain and its management (Chopra and Meindl, 2001). "There is nothing more important within the realm of supply chain management than the management of inventory..." (Levy and Dhruv, 2000, p. 416). As such, decisions regarding inventory replenishment have a direct effect on supply chain performance. Developed relatively recently, VMI was one system or tool for use in inventory management decision-making. Originally, its use and benefits were documented by a few authors with the primary research being conducted by Blatherwick (1998), Cachon and Fisher (1997), Fraza (1998), Clark and Hammond (1997) and Waller et al. (1999).

Recently more research has been done, including attempts to quantify benefits by modeling VMI in supply chains. Min and Zhou (2002) provided a recent literature review on supply chain modeling. They noted that there have been many theoretical models of inventory management in the supply chain but, within the stochastic and hybrid models represented by this paper's content, little empirical research has been gathered. They also note the need for simulation models to evaluate dynamic decision rules in supply chain management. The following paragraphs classify this recent modeling research into three areas: theoretical mathematical models, discrete event simulation models and those models used to analyze the reduction of the bullwhip effect created by VMI.

\subsection{Theoretic mathematical models}

As mentioned earlier, Chaouch (2001) developed a mathematical inventory model to evaluate the trade- offs between inventory costs, stockouts and shipping frequency. A general conclusion offered by that model was that the appropriate balance is not always intuitively clear and that businesses must try to quantitatively model their situation to obtain the optimal decision.

Fry et al. (2001) developed a mathematical model to evaluate a specific VMI relationship they termed the $(z$, $Z$ ) type of contract where there are minimum and maximum inventory levels where the supplier must pay a penalty for falling outside the boundaries. Their model assumed a periodic inventory review policy. They showed the optimal inventory policy to be a "replenishment-up-to" policy.

Dong and $\mathrm{Xu}$ (2002) also developed a mathematical model to evaluate the benefits of VMI but did so in light of separating them out so as to determine to whom the benefits accrue, buyer or supplier. Their model indicated that, under certain conditions (particularly the short term); the main benefit accrues to the buyer.

Choi et al. (2004) proposed a theoretical deterministic mathematical model that evaluated the effect of supplier service levels on customer service levels finding it irrelevant to end-customer service levels.

Mishra and Raghunathan (2004) created a mathematical model to analyze competition between sellers in a VMI environment and proposed that VMI increases the competition between such manufacturers and that retailers may see this competition as another benefit to using VMI.

Lo and Wee (2005) proposed a mathematical model, based on Cetinkaya and Lee (2000) to assist in coordinating the shipping function in a VMI system. The quantitybased deterministic model helped to reduce transportation costs in an $(s, S)$ system better than a time-based model.

Likewise, Bertazzi et al. (2005) created a theoretical deterministic mathematical model comparing an order-upto policy to an order-up-to with a dump off at the last stop, finding not only does VMI lower costs over traditional methods but also that the latter model performed better than a pure order-up-to model.

Using basic mathematical inventory models, Chen et al. (2005) compared quantity-based and time-based mathematical inventory models for analyzing joint stock replenishment and shipment consolidation in a VMI environment. They found that quantity-based models performed better based on traditional inventory modeling costs.

Bernstein et al. (2006) examined the effect of VMI on pricing in supply chains using a theoretical deterministic mathematical model. Their model suggests that VMI creates a sufficient economic condition whereby VMI allows for channel coordination using simple pricing schemes.

The model created by Tan et al. (2007) also indicated that the optimal ordering policy is also an order-up-to system based on the kind of demand information supplied by a VMI system.

Yao et al. (2007) also evaluated the effect of implementing VMI on inventory-carrying costs. Their mathematical model used deterministic parameters such as demand 
for the product. While their theoretical model confirmed that lower inventory-carrying costs should result, the authors stated that empirical research was needed to support such models.

Nachiappan et al. (2007) used nonlinear integer programming to develop an IS model that determines optimal transaction quantities to maximize channel profit. This model was then used to compute optimal prices. They mention that "there is a paucity of studies that deal specifically with the dynamics of the supply chain and how data collected in these systems can be used to improve their performance" (Nachiappan et al., 2007, p. 2480).

Jarugumilli and Grasman (2007) developed and used mathematical modeling to provide evidence of the benefits of radio frequency identification (RFID) in a VMIcontrolled supply chain.

\subsection{Discrete event simulation}

Yang et al. (2003) used a discrete event simulation model (SLAM II) and theoretical data to evaluate the impact of six operational factors on a two-level VMI system. The general conclusion was that those 6 factors (demand variability, the review interval, the number of buyers, availability of information, volume and product flexibility) all had significant effects on the performance of the supply chain in a VMI environment.

Angulo et al. (2004) created a four-tier simulation model, using Arena, to evaluate the information sharing effects of variation in demand and lead time on a VMI system. Their performance measures were average inventory levels, fill rates and the associate costs. They calculated average carrying cost as $20 \%$. Their study found that while information delay impacted the performance measures significantly (particularly vendor inventory levels), information accuracy did not.

Comparing both continuous and discrete models using Simulink, White and Censlive (2006) discussed appropriate production delay and model strategies for VMI. They concluded that the appropriative delay depends on the level of aggregation and order scheduling.

\subsection{VMI and the bullwhip effect}

(Disney and Towill, 2003a) and (Disney and Towill, 2003b) produced two articles regarding VMI and the bullwhip effect. The first article demonstrates, through mathematical modeling and simulation that VMI helps to dampen the bullwhip effect focusing on that portion of the bullwhip effect created by what the authors term the "Forrester effect" (consisting of non-zero lead times and demand signaling processing). The findings were that VMI "shortened" the supply chain pipeline resulting in the halving of the bullwhip effect.

The second article investigates a similar topic but includes three additional sources of the bullwhip effect. Their findings indicated that the sources of order batching and rationing and gaming can be eliminated while the other two can be reduced.
Disney, along with his coauthors, also looked at VMI and transport operations (Disney et al., 2003) as well as VMIs interaction with e-business (Disney et al., 2004). The former article focused on the use of batching in supply chain logistics to avoid the costs of less-than-truckload rates. It found that VMI does incorporate batching which helps it to avoid the normal trade-off between improved dynamic properties and minimizing transportation costs when compared to "traditional" supply chain systems.

The latter article is of particular interest to this study since it indicates that the simpler the information system used to facilitate VMI in the supply chain, the more effective it may be. The authors also state that simple robust supply chain models can be very effective in evaluating the impact of information technology on supply chain dynamics.

The theory and research to this point, however, has generally been limited to large, well-capitalized organizations and supply chains. This study intended to determine whether the VMI customer-relationship model, which has been well documented in those supply chains, had the ability to affect the performance measures in a type of supply chain to which it had never been applied and in a type of relationship within that supply chain which has seen little research.

\section{Methodology}

\subsection{Introduction}

Discrete event simulation was used to create both a representation of the existing business environment and an alternative model to be tested against the base model. The simulation software selected was PROMODEL ${ }^{\circledR}$, developed by PROMODEL Corporation of Orem, Utah. Simulation was chosen because its ability to handle the stochastic variables in the dynamic problem domain was generally more desirable than that of static deterministic models. The problem domain contained a large amount of environmental uncertainty and dynamic situations where events were time dependant. Simulation was noted as being generally better able to cope with this variation and time dependency (Irani et al., 2000). Simulation modeling had been used to analyze various service processes (Lee and Elcan, 1996). Greasley and Barlow (1998) looked at simulation in reengineering the police custody process in the United Kingdom. Waller et al. (1999) used simulation to study VMI at Hewlett-Packard. Waller's study also indicated that simulation had been used to study VMI at the Campbell's Soup Company.

\subsection{Experimental design}

Actual performance measures were selected and prioritized using information obtained in interviews with cooperative fuel delivery managers and based on what they considered important measures of performance. In addition, certain concepts were determined in the planning stages as being critical to measuring the sys- 
tem. These projected performance measurements of the model, based on operations and logistics theory, were costs and service levels as measured by stockouts, generated by each model scenario. Final validation used the data gathered from the cooperative to compare the model results with actual results from the cooperatives.

The objective was to calculate costs (delivery costs, holding costs) for the systems to determine if there was a sufficient cost advantage in the technology-enabled model to justify the extra costs associated with the capital expenditures needed. The purpose of this objective was to provide basic comparative information to those cooperatives in mature markets that were dealing with increasing competition and competed on the basis of price and service.

Based on the objective, a model of the most common organizational delivery system (the base model) was developed along with other models or scenarios, derived from systems in use, which captured possible alternatives that would accomplish the objective. Finally, the proxy for the technology-enabled VMI system (the Monitored Fuel Level model) was created. The model scenarios are described in more detail in Table 1.

Three performance measures were identified for analysis. Costs incurred in the delivery of fuel, inventory costs for fuel and total stockouts of fuel at destination locations. These are presented in Table 2. These performance measures were determined through interviews with representatives of the agricultural cooperatives.

Resource utilization is also important from an agricultural cooperative perspective. However, after initial study and follow-up discussions, it was determined that delivery costs were a suitable surrogate for resource utilization. Because of potential issues of multi-co linearity, it was determined that the analysis should not include both criteria.

Due to the competitive climate being modeled, it was determined that total stockouts represented an order-qualifying criterion. Further reductions in stockouts would not increase the likelihood of selection by a customer; however, an increase in the number of stockouts would likely increase the likelihood that a customer would choose an alternative provider.

Price is the primary Order Winning criterion for the competitive environment of farm fuel delivery. Given the low margins earned on farm fuel delivery, remaining competitive on price requires reduced costs. Two cost types, farm fuel delivery costs and inventory holding costs, constitute the measurable costs addressed.

The experimental design was constructed along the lines described by Law and Kelton (2000) where the factors consisted of the different model scenarios. The alternative scenario tested a different inventory and delivery method that was then compared to the base model. "In experimental-design terminology, the input parameters and structural assumptions composing a model are called factors and the output performance measures are called responses" (Law and Kelton, 2000, p. 622).
Table 1. Simulation model alternatives

Model name/abbreviation Model description

Next Closest (NC)

Orders for fuel are placed by customers as fuel is consumed. The sequence of visits is based on the proximity of each location to the last location served, beginning with the cooperative. Routing from farm to farm is based on the model selecting the shortest route between any two individual farms that ordered fuel.

First Come First Served Orders for fuel are placed by customers as (FCFS) fuel is consumed. The sequence of visits is based on the order in which they are received. Routing from farm to farm is based on the model selecting the shortest route between any two individual farms that ordered fuel.

Fixed Interval 1 (weekly milk run) (FI1)

No orders for fuel are placed. Deliveries are made to each farm once per week based on a fixed route (each route is used once per week) regardless of fuel use based on a predetermined fixed route.

Fixed Interval 2 (biweekly milk run) (FI2)

No orders for fuel are placed. Deliveries are made to each farm twice per week based on a fixed route (each route is used twice per week) regardless of fuel use based on a predetermined fixed route.

Keep Full basis (KF) Orders for fuel are placed when the fuel level in the farm tank reaches a specified level. When one farm on a predetermined fixed route orders fuel, the truck delivers fuel to all farms on that predetermined route regardless of the fuel use at the other farms.

Monitored Fuel Level This model assumes there is a fuel monitor(MFL) ing system in place whereby the cooperative is regularly apprised of the level of fuel remaining in each farm tank. Delivery orders are generated at the cooperative when the fuel level in the farm tank reaches a predetermined level. The sequence of visits is based on the orders received and the proximity of each requesting location to the last location served, beginning with the cooperative. Routing from farm to farm is based on the model selecting the shortest route between any two individual farms.

\subsection{Model assumptions}

In collecting high-quality information and data, designing the alternative system configurations, and in making the model assumptions, a variety of sources were used including conversations with experts, observations of the system, existing theory, relevant results from other simulation studies and the experience and intuition of the modelers (Law and Kelton, 2000). The different scenarios were based on delivery designs suggested either by literature or by the cooperative fuel managers in interviews. Assumptions included the three trigger levels for the VMI models. The three trigger levels used were: TL1, TL2, and TL3 which corresponded to 25\% empty, $50 \%$ empty, and 75\% empty, respectively (e.g., TL1 was 
Table 2. Performance measures

\begin{tabular}{ll}
\hline Variable name & Variable description and function \\
\hline Cost & $\begin{array}{l}\text { This measure examined the cost to the dis- } \\
\text { tributor of using the available resource }\end{array}$ \\
Holding costs (hold cost) & This measure examined the cost, to the sys-
\end{tabular}
tem of buyers, of holding inventory
Stockouts

This measure examined the number of times buyers ran out of product and acted as a service quality indicator

\begin{abstract}
Calculation
Calculated as the sum of the fuel cost, fixed costs and driver's wages converted into an hourly cost figure.

Calculated as the average inventory at all farms times $20 \%$ of the value of that inventory. Average inventory was calculated as: ((beginning inventory-ending inventory $) / 2) \times(($ ending time-beginning time)/365). A total average inventory for each farm was derived from summing each individual average inventory figure. By summing each farm's total average inventory, a grand total average inventory figure for the system was obtained for the time period of the simulation run.
\end{abstract}

Calculated by a counter that increased each time an individual tank reached a fuel level of zero. reached when a tank was $25 \%$ empty). These levels were determined from conversations with eight cooperative fuel managers which indicated that these were the general levels, other than empty, at which time customers ordered fuel. These levels were generally bounded by the lower level (75\% empty) and the upper level (only 25\% empty) with the third measure selected as a midpoint.

Other assumptions were also made during the development of the model. It was assumed that all demand for diesel fuel was met only by the single cooperative. In other words, the farm units did not obtain diesel fuel from other sources during the periods of data collection that would change the actual amount of total fuel consumed by the farmers. While the market is extremely competitive, customers do remain loyal unless stockouts increase or prices do not remain competitive. It was also assumed that all of the customers received all of the fuel shown on the delivery tickets. This meant that there were no crop-sharing agreements involved whereby the delivery tickets only showed the charge for the landlord's half of the fuel and not the actual delivery of fuel.

For delivery locations, the number of farms was kept constant. While cooperatives gained and lost customers periodically, the models assumed that the customer base remained at a constant 50 customers. It was assumed that the distance from the farms to the cooperative remained constant and that there was only one cooperative, or delivery point.

There were several assumptions regarding the truck. The models each assumed there was only one truck and that deliveries were made from 7:00 a.m. until route completion, Monday through Saturday. It was further assumed that breaks were taken at convenient times/locations throughout the day so that no additional travel was necessary to accommodate breaks.

It was initially assumed that there were three possible levels of costs for each parameter. That is, a high, medium and low level for inventory holding cost rates (tied to fuel costs), delivery cost rates and driver wages. However, preliminary results indicated that levels of costs did not matter, just the relationships between costs. Further, agricultural cooperative members indicated these costs were highly correlated in practice, i.e., if inventory holding cost rates were high, then delivery cost rates were also likely to be high. Further, as long as they were similar, whether high, medium or low, the same results were provided. Therefore, in final analysis, fuel prices and delivery rates were set at the medium level and driver costs were set at $\$ 10$ per hour. These costs remained constant over the period of the simulation as did the period of time the driver worked, which was assumed to be from 7:00 a.m. until 5:00 p.m. Monday through Saturday. It was assumed the driver ate lunch on the road as no downtime was allocated for this. Given the route structure, no overtime was paid if routes took longer to complete. It was assumed that the set-up or ordering cost of $\$ 10$ per order and the fixed cost of operating the truck at $\$ 0.40$ per mile, obtained from cooperative fuel managers, remained constant. The speed of the delivery truck was set at a constant 30 miles per hour assuming that this average would account for higher speeds on highways and lower speeds at corners and on rural gravel roads. These assumptions came directly from interviews with the eight cooperative fuel managers.

It was assumed that all farms owned 1000-gallon tanks. This was felt necessary as the model randomly assigned distributions to the farms. Since there was a wide variation in the size of the distributions and since it was not possible to determine ahead of time which farm would have high or low demand, the simplest solution was to assign all farms a tank size that would contain sufficient fuel to handle the majority of demand amounts. While not fully realistic, the method of ordering fuel and refilling the tanks in the model appeared to nullify many of the drawbacks of using this average.

There was no control for seasonal effects. Since data were collected over a multi-year period, the overall fuel usage distributions offset one another. Since the goal was to model overall system fuel demand and delivery over a long period of time, individual farm patterns were not needed. The model did not distinguish between different kinds of fuel use. Whether for fieldwork, irrigation units, livestock operations or snow removal, the purpose for which the farmer obtained the fuel was not relevant. It was assumed the farmer would use fuel year-round. 


\subsection{Analysis procedure}

The results were analyzed by comparing the means and standard deviations of the alternative models to those of the base model in terms of the output measures. This analysis technique was proposed for comparing alternative simulation system configurations by Law and Kelton (2000).

The output measures were to be prioritized or classified using the Order Qualifier/Order Winner concept of competitive dimensions or priorities from operations management literature (Hill, 2000). Comparisons were based on the premise that stockouts were the Order Qualifier and that an increase in stockouts would be unacceptable due to the loss of business that would result. Paired $t$-tests were used to determine if there was a statistically significant increase in the performance measure, stockouts, between the base model and the alternatives. Any model that showed a statistically significant increase in stockouts would be eliminated from further consideration. Those models not showing a statistically significant increase in stockouts would then be tested on the remaining output cost measures. These measures were the Order Winners.

Individual customer fuel delivery data were collected from two central Nebraska cooperatives. This information included individual farm fuel delivery dates and amounts on 277 customers over a 2-year period. This information was then converted into demand distributions to be used in the simulation.

The Monitored Fuel Level model and the Keep Full model both had three levels of remaining fuel volumes as the trigger for ordering additional fuel. To generate the data necessary to analyze the hypotheses, each of the 30 simulation model scenarios was replicated for 100 times or the equivalent of 100 years of data. The number of replications used to verify the model was based on the statistical procedures stated by Harrell et al. (1996) and Law and Kelton (2000). The simulations were carried out on six Dell Pentium III desktop computers. Each of the 30 runs took approximately $8 \mathrm{~h}$ of computing time for a total of approximately 240 computing hours.

\section{Results}

The mean and standard deviation for each performance measure on each of the models were recorded and are presented in Table 3.

Based on the objectives and design of the experiment, the means and standard deviations of the performance measure of the base model, Next Closest and those of the five alternative models were compared using paired $t$-tests. In addition, since the First Come, First Served model was serving as a comparison to a typical service system; providing good customer service response rates, but poor delivery efficiency; it was treated as an alternative base model, or worst case scenario. Paired $t$-tests were also used to compare the First Come, First Served model to the remaining four alternative models.

\subsection{Stockouts incurred}

The first step, based on the experimental design, was to determine which models had stockout levels that were not significantly higher than the base model. This was to establish which models met the order-qualifying criteria of possessing a service level that was no worse than the base model. Paired $t$-tests for differences in two means were run for the base model (Next Closest) and each alternative model at a 0.05 significance level and are summarized in Table 4.

The results indicated that only the First Come, First Served model, the Fixed Interval at two visits per week, the Monitored Fuel Level at trigger level 1, or 25\% empty, and all three of the Keep Full models were not significantly higher in terms of the number of stockouts. The statistical analysis indicated that, when compared to the base model, these six alternative model scenarios were not significantly worse in the number of stockouts incurred. This meant that those six scenarios were at least as good, in terms of stockouts, as the base model. This was important as the service level of the delivery system was considered as an Order Qualifier for the system. In order for a model to be considered as a candidate for improvement over the base model, it must first have shown that it was not detrimental to the service level provided by the base model. The six models that met this screening criterion were the First Come, First Served model, the Fixed Interval at two visits per week, the Monitored Fuel Level at trigger level 1 and all three trigger-level scenarios of the Keep Full model. The remaining three models, Fixed Interval 1 and the Monitored Fuel Levels at trigger levels 2 and 3 , were therefore eliminated from further consideration. The six qualifying models were then compared to the base model in terms of the remaining performance measurements: truck cost and holding costs.

\subsection{Farm fuel delivery (trucking) and holding costs}

The next step was to evaluate the qualifying models against the base model in terms of the remaining performance measures. While the three Keep Full models were substantially higher than the base model in terms of trucking costs, the Monitored Fuel Level model at trigger level 1 and the FCFS model were both very close to the base model. The $p$-values from paired $t$-tests comparing those two models against the base model indicated, however, that they were statistically significantly different as seen in Table 5.

The First Come, First Served model was slightly but statistically significantly higher than the base model (NC) in trucking costs. Since the deliveries in the base model underwent an additional step of determining the closest proximity from the last delivery, it was anticipated that it would have slightly lower trucking costs than the First 
Table 3. Summary output results

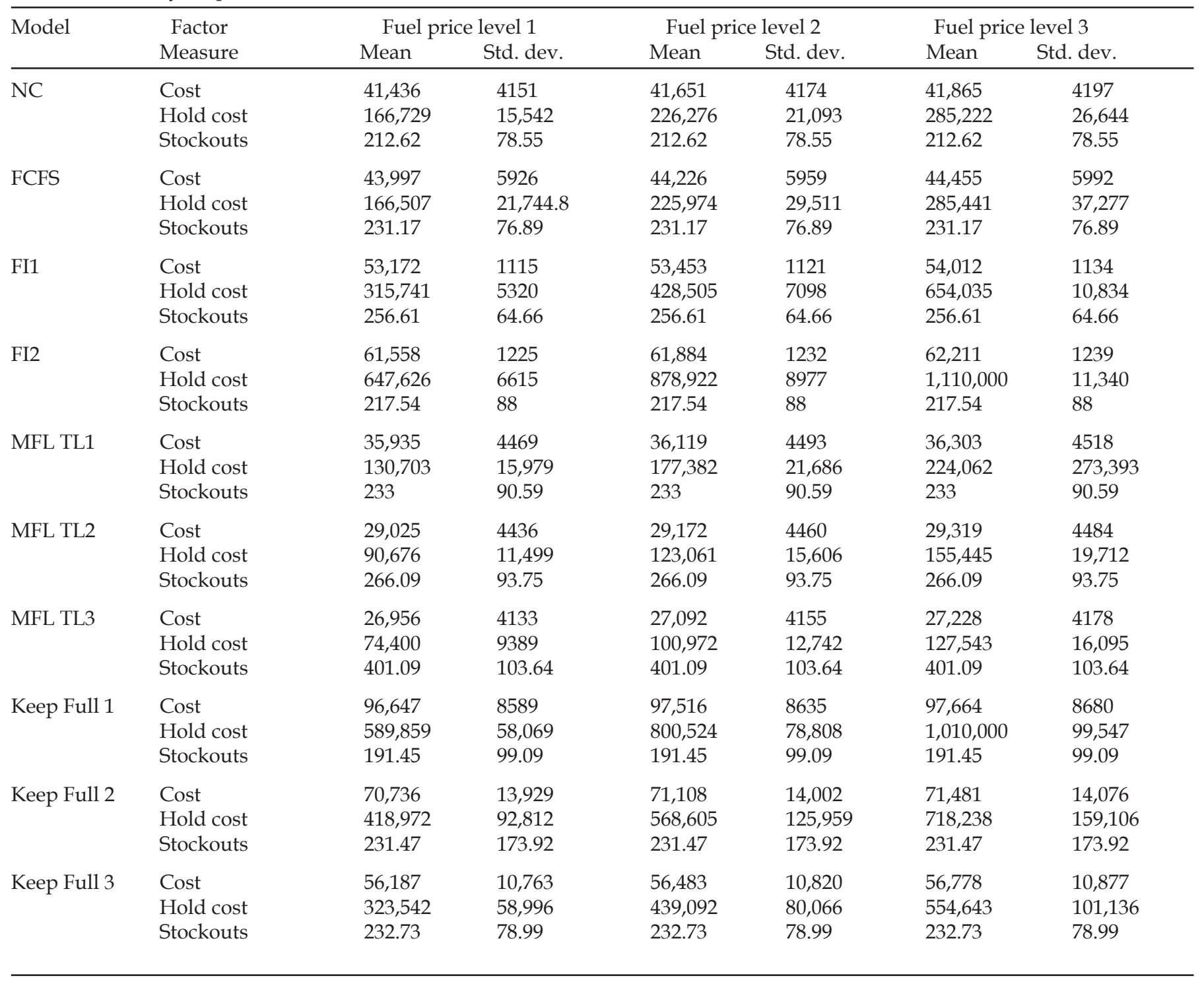

Come, First Served. The results confirmed that. Therefore, even though holding costs were not significantly different than the base model, the FCFS model did not meet the established objectives and was not considered an improvement over the base model. It did, however, meet expectations of performance as expected, providing additional evidence of model validity. The holding cost results are summarized in Table 6.

The three Keep Full models produced substantially higher trucking costs and higher holding costs at all three trigger levels. As with the Fixed Interval models, the truck in the Keep Full scenarios had to make a complete route any time a single farm on that route needed fuel. Unlike the Fixed Interval model, however, there had to be a need for fuel on at least one farm to initiate the scheduling of the route. It also meant, however, that the truck could deliver on the same route more than two times a week, increasing the trucking and holding costs.
Table 4. $p$-values from paired $t$-tests of means for stockouts

\begin{tabular}{lll}
\hline Stockouts & & \\
& \multicolumn{1}{c}{$\mathrm{NC}$} & $\mathrm{FCFS}$ \\
\hline $\mathrm{NC}$ & & \\
FCFS & $0.093061^{*}$ & \\
FI1 & $2.43 \mathrm{E}-05$ & 0.012109 \\
FI2 & $0.677059^{*}$ & $0.244871^{*}$ \\
MFL TL1 & $0.090755^{*}$ & $0.877757^{*}$ \\
MFL TL2 & $1.99 \mathrm{E}-05$ & 0.004414 \\
MFL TL3 & $6.39 \mathrm{E}-33$ & $7.49 \mathrm{E}-29$ \\
KF TL1 & $0.095667^{*}$ & 0.001785 \\
KF TL2 & $0.324475^{*}$ & $0.987429^{*}$ \\
KF TL3 & $0.072557^{*}$ & $0.887605^{*}$ \\
\hline
\end{tabular}

*Not significant using a $0.05 \alpha$, total $d f=198$, critical $t$-value: \pm 1.972. 
Table 5. $p$-values from paired $t$-tests of the means for trucking costs

\begin{tabular}{|c|c|c|c|c|c|c|c|c|}
\hline \multicolumn{3}{|c|}{ Truck cost-fuel price 1} & \multicolumn{3}{|c|}{ Truck cost-fuel price 2} & \multicolumn{3}{|c|}{ Truck cost-fuel price 3} \\
\hline & $\mathrm{NC}$ & FCFS & & & & & & \\
\hline NC & & & $\mathrm{NC}$ & & & $\mathrm{NC}$ & & \\
\hline FCFS & $0.000499^{*}$ & & FCFS & $0.0005^{*}$ & & FCFS & $0.000498^{*}$ & \\
\hline FI1 & $4.69 \mathrm{E}-69^{*}$ & $3.89 \mathrm{E}-35^{*}$ & FI1 & $4.63 \mathrm{E}-69^{*}$ & $3.85 \mathrm{E}-35^{*}$ & FI1 & $1.26 \mathrm{E}-70^{*}$ & $1.58 \mathrm{E}-36^{*}$ \\
\hline FI2 & $4.06 \mathrm{E}-57^{*}$ & $2.98 \mathrm{E}-73^{*}$ & FI2 & $1.7 \mathrm{E}-108^{*}$ & $3.01 \mathrm{E}-73^{*}$ & FI2 & $1.7 \mathrm{E}-108^{*}$ & $3 \mathrm{E}-73^{*}$ \\
\hline MFL TL1 & $1.65 \mathrm{E}-16^{*}$ & $7.36 \mathrm{E}-22 *$ & MFL TL1 & $1.64 \mathrm{E}-16^{*}$ & $7.31 \mathrm{E}-22 *$ & MFL TL1 & $1.65 \mathrm{E}-16^{*}$ & $7.31 \mathrm{E}-22 *$ \\
\hline KF TL1 & $4.9 \mathrm{E}-126^{*}$ & $5.5 \mathrm{E}-115^{*}$ & KF TL1 & $1.5 \mathrm{E}-126^{*}$ & $1.6 \mathrm{E}-115^{*}$ & KF TL1 & $4.9 \mathrm{E}-126^{*}$ & 5.7E-115* \\
\hline KF TL2 & $7.21 \mathrm{E}-50^{*}$ & $1.5 \mathrm{E}-42^{*}$ & KF TL2 & $7.12 \mathrm{E}-50^{*}$ & $1.49 \mathrm{E}-42^{*}$ & KF TL2 & $7.03 \mathrm{E}-50^{*}$ & $1.48 \mathrm{E}-42^{*}$ \\
\hline KF TL3 & $1.09 \mathrm{E}-27^{*}$ & 4.34E-19* & KF TL3 & $1.08 \mathrm{E}-27^{*}$ & 4.3E-19* & KF TL3 & $1.06 \mathrm{E}-27^{*}$ & $4.28 \mathrm{E}-19^{*}$ \\
\hline
\end{tabular}

*Significant using a $0.05 \alpha$, total $d f=198$, critical $t$-value: \pm 1.972 .

Table 6. $p$-values from paired $t$-tests of the means for holding costs

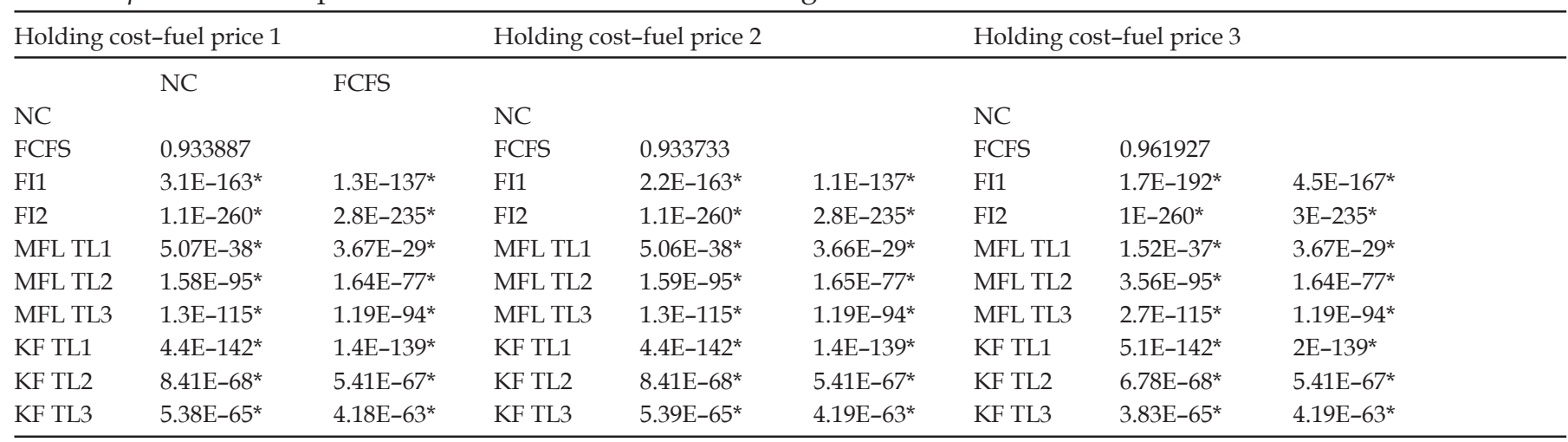

*Significant using a $0.05 \alpha$, total $d f=198$, critical $t$-value: \pm 1.972 .

The Monitored Fuel Level model at trigger level one, or $25 \%$ empty, showed lower costs in both categories, when compared to the base model. The comparisons indicated that, of the six models showing no significant difference in stockout occurrences, only the model representing the VMI concept, with a Monitored Fuel Level triggered delivery schedule, met the research design objectives of an improved level of resource utilization and lower costs than the base model. The conclusion was that an inventory and delivery system incorporating the technology-enabled VMI concepts outperformed existing delivery system designs.

\section{Discussion}

In summarizing these results, VMI did reduce costs in the farm delivery routes simulated. In addition, customer service levels were improved or showed no significant difference between the existing system and the proposed VMI alternatives.

The original basis for this study was the proposition that changes in technology have allowed for improvements in the flows of information within supply chains. In the base model, fuel was delivered as soon as it was consumed on the farm. Since the timing and amounts of the demand were based on data collected from the cooperatives regarding farm fuel deliveries, this model produced deliveries that duplicated the current delivery practices of cooperatives. The experimental model, Monitored Fuel Level, represented not only a change in the flow of information but also a change in which member of the supply chain took responsibility for inventory management decisions. The Monitored Fuel Level model represented the scenario where the agricultural service firm obtained fuel-level information from the farm and then assumed the responsibility for inventory management. The results of the study indicated that, by altering the flow of information and the point of decision-making, costs for both members of the supply chain could be improved without decreasing service levels. With trucking cost savings of $\$ 5501$ and holding cost savings of $\$ 26,026$ spread across the average of 596,969 gallons delivered in the Monitored Fuel Level model, the overall cost savings of this model amounted to an average of $\$ 0.07$ per gallon. This amount saved is also the amount that the cooperative managers had stated that they were losing on fuel deliveries. This becomes the basis for calculating the amount of capital expenditure needed to implement such 
a system. Because of the number of potential alternatives for gathering information for the VMI models and the ever changing costs and new innovations, these capital expenditures were not modeled directly in the system. Rather, the savings generated are intended as a means to determine whether a specific alternative can be implemented, given the individualized costs at the time.

A leading provider of tank monitoring equipment, Centeron, lists on its website (wirelessmonitoring.centeron.net) costs of approximately $\$ 475$ per tank plus $\$ 100$ installation and a $\$ 20 /$ year data center charge. If one multiplies this times the 50 tanks assumed in the simulation and considering that the $\$ 575$ is a one-time charge, the system proves to be cost effective. With the 50 tanks used in the study, that charge is $\$ 28,750$ or $\$ 0.05$ per gallon based on the 596,969 gallons delivered).

The improvements in supply chain performance documented by this study may be added to those currently noted in research with the additional knowledge that this supply chain tool has the potential to create improved competitive advantages in supply chain structures heretofore untested. This knowledge improves VMI's generalizability and the generalizability of this study.

Of at least equal importance, however, was that the study provided sound experimental evidence that the principles of VMI produces positive performance measurement differences in the uniquely structured supply chain of the agricultural service firm. This evidence opens the door for performance improvements in many areas of this industry and other industries structured in a similar manner.

With the growing importance of SCM and the increased competition between firms and their supply chains, the ability to translate successful management tools, the ones that provide competitive advantages, from one industry to another is of critical importance. With the knowledge, produced by this study, that VMI could be transferred between two differently structured supply chains also meant that it might be possible to transfer other tools once considered the sole domain of manufacturing.

The experimental model created to simulate a VMI type of inventory control and delivery system incurred lowered costs than the model of the current industry practices while, at the same time, maintained the service level needed to meet the order-qualifying criteria.

\subsection{Managerial implications}

There are several implications for management deduced from these results. The study found that, by allowing the supplier to monitor the inventory levels of the customer, the supplier was able to make restocking decisions that allowed it to schedule more efficient routes less often that reduced the amount of time it took for the delivery resource to maintain adequate fuel inventory at the customer's location. This justifies the expenditures needed to build the needed infrastructure for such a system.
In addition, it was possible to create a delivery system using VMI concepts that reduced the cost of both transporting the inventory to the customer and the cost to that customer for holding inventory. By allowing the supplier to determine when inventory was needed, excess inventory was avoided and the cost of delivering that excess inventory was eliminated.

\subsection{Conclusions}

This study provided empirical evidence that sufficient economic benefits could be achieved with the use of a technology-enabled VMI system such that the firm can justify spending the money necessary to create the infrastructure to support it. The models, while modeled on a specific type of business, were still generic enough that the results could be generalized to many types of highly distributed, variable demand delivery systems.

In addition, this study provided the first information regarding the performance of such technology usage concepts in a unique supply chain, that of a rural service firm. The study was also one of very few works that attempted to transfer theory and practice from the production and operations management area to the agricultural area.

Another strength of the study was that it provided the basis for an implementable solution to an industry problem. It therefore provided practical implications for business.

The software used to generate the models has been in widespread commercial use. Businesses or consultants could use this study as the basis for the design of a system for daily or weekly route construction. As mentioned, the model itself could be used as a presentation tool to graphically demonstrate the benefits of VMI to managers.

This study provided the basis for simulation model construction for a variety of application areas in delivery and logistics. While developed based on a cooperative delivery system, its applicability stretches to any highly distributed yet geographically concentrated logistics problem dealing with variable demand patterns. One such scenario is illustrated by the advent of Internetbased home grocery delivery firms such as Peapod (Peapod, 2008). Another application could be the use of such tools by a lawn care service. Another example would be its use in the multi-location, multi-level environment of the vending machine replenishment. Vendors must efficiently plan the movement of employees and product within a multi-story building that contains several vending machines on different floors, each facing a variable demand pattern. In this case, and in addition to the model itself, a RFID solution to the VMI system could eliminate the need for an employee to first visit each machine to determine the need for refilling before stocking either the truck or the delivery cart.

One limitation of the study was that the model representing the technology system did not include an actual forecasting model. In a true VMI setting, the vendor 
would use past records of demand to calculate the scheduling of delivery routes. Another limitation of the study was that the cost of stockouts to either the vendor or the customer was not addressed. These costs could vary, in this agricultural setting, based on the time of year and the type of farming operation involved.

This study used a unique set of firms in a unique industry, cooperatives in the agricultural industry. The type of data collected and the type of firm modeled may potentially limit some of the generalizability of the results.

While only larger, more capital rich organizations have been able to adopt the commercial integration applications, such as ERP, smaller firms and supply chains have the opportunity to gain many of the advantages of their more powerful competition through less expensive means. One of the benefits of this study was to demonstrate that the smaller, more independent business, specifically the rural agricultural service firm, has the opportunity to benefit from the experiences of the larger companies and integrate them into their own operations to gain a competitive advantage. In the current global business environment, this type of competitive advantage could be the difference between success and failure.

\subsection{Future research}

This study presents several areas for future research including the implementation of the study. An empirical study of current delivery methods in similar highly distributed systems and the use of VMI techniques by those systems have not been done. Coinciding with this would be to collect data on what alternatives local managers have considered for improving their delivery system. Little empirical data have been collected, particularly in the small business sector, regarding delivery systems and VMI.

This study has also indicated the need for additional study regarding this type of supply chain including the need to examine the issue of technology transfer and adoption rates and factors. This study also focused only on the relationship between the cooperative and the farm customer. The effects of a VMI implementation within this relationship would likely have repercussions further up the supply chain. An expanded look at those effects, back up the supply chain towards the fuel distributor, is needed.

\section{References}

Achabal et al., 2000 - D. D. Achabal, S. H. McIntyre, S. A. Smith and K. Kalyanam, A decision support system for vendor managed inventory, Journal of Retailing 76 (4) (2000), pp. 430-454.

Angulo et al., 2004 - A. Angulo, H. Nachtmann and M. A. Waller, Supply chain information sharing in a vendor managed inventory partnership, Journal of Business Logistics 25 (1) (2004), pp. 101-120.

Bechtel and Jayaram, 1997 - C. Bechtel and J. Jayaram, supply chain management: A strategic perspective, International Journal of Logistics Management 8 (1) (1997), pp. 15-27.
Bernstein et al., 2006 - F. Bernstein, F. Chen and A. Federgruen, Coordinating supply chains with simple pricing schemes: The role of vendor-managed inventories, Management Science 52 (10) (2006), pp. 1483-1492.

Bertazzi et al., 2005 - L. Bertazzi, G. Paletta and M. G. Speranza, Minimizing the total cost of an integrated vendor-managed inventory system, Journal of Heuristics 11 (2005), pp. 393-419.

Blatherwick, 1998 - A. Blatherwick, Vendor-managed inventory: Fashion fad or important supply chain strategy?, Supply Chain Management 3 (1) (1998), pp. 10-11.

Cachon and Fisher, 1997 - G. Cachon and M. Fisher, Campbell soup's continuous replenishment program: Evaluation and enhanced decision rules, Production and Operations Management 6 (3) (1997), pp. 266-276.

Cetinkaya and Lee, 2000 - S. Cetinkaya and C.-Y. Lee, Stock replenishment and shipment scheduling for vendor-managed inventory systems, Management Science 46 (2) (2000), pp. 217-232.

Challener, 2000 - C. Challener, Taking the VMI step to collaborative commerce, Chemical Market Reporter 258 (21) (2000), pp. 11-12.

Chaouch, 2001 - B. A. Chaouch, Stock levels and delivery rates in vendor-managed inventory programs, Production and Operations Management 10 (1) (2001), pp. 31-44.

Chen et al., 2005 - F. Y. Chen, T. Wang and T. Z. Xu, Integrated inventory replenishment and temporal shipment consolidation: A comparison of quantity-based and time-based models, Annals of Operations Research 135 (2005), pp. 197-210.

Choi et al., 2004 - K.-S. Choi, J. G. Dai and J.-S. Song, On measuring supplier performance under vendor-managed inventory programs in capacitated supply chains, Manufacturing $\mathcal{E}$ Service Operations Management 6 (1) (2004), pp. 53-72.

Chopra and Meindl, 2001 - S. Chopra and P. Meindl, Supply Chain Management: Strategy, Planning, Operation (first ed), Prentice Hall, Upper Saddle River (2001).

Clark and Hammond, 1997 - T. H. Clark and J. H. Hammond, Reengineering channel reordering processes to improve total supply-chain performance, Production and Operations Management 6 (3) (1997), pp. 248-265.

Danese, 2006 - P. Danese, The extended VMI for coordinating the whole supply network, Journal of Manufacturing Technology and Management 17 (7) (2006), pp. 888-907.

De Toni and Zamolo, 2005 - A. F. De Toni and E. Zamolo, From a traditional replenishment system to vendor-managed inventory: A case study from the household electrical appliances sector, International Journal of Production Economics 96 (2005), pp. 63-79.

Disney and Towill, 2003a - S. M. Disney and D. R. Towill, The effect of vendor managed inventory (VMI) dynamics on the bullwhip effect in supply chains, International Journal of Production Economics 85 (2003), pp. 199-215.

Disney and Towill, 2003b - S. M. Disney and D. R. Towill, Vendor-managed inventory and bullwhip reduction in a two-level supply chain, International Journal of Operations \& Production Management 23 (5/6) (2003), pp. 625-651.

Disney et al., 2003 - S. M. Disney, A. T. Potter and B. M. Gardner, The impact of vendor managed inventory on transport operations, Transportation Research Part E 39 (2003), pp. 363-380.

Disney et al., 2004 - S. M. Disney, M. M. Naim and A. T. Potter, Assessing the impact of e-business on supply chain dynamics, International Journal of Production Economics 89 (2004), pp. 109-118. 
Dong and Xu, 2002 - Y. Dong and K. Xu, A supply chain model of vendor managed inventory, Transportation Research Part E 38 (2002), pp. 75-95.

Dorling et al., 2006 - K. Dorling, J. Scott and E. Deakins, Determinants of successful vendor managed inventory relationships in oligopoly industries, International Journal of Physical Distribution \& Logistics Management 36 (3) (2006), pp. 176-191.

Emigh, 1999 - J. Emigh, Vendor-managed inventory: Financial and business concepts in brief, Computerworld 33 (34) (1999), p. 52.

Fox, 1996 - M. L. Fox. Integrating vendor-managed inventory into supply chain decision-making. Paper presented at the APICS 39th International Conference Proceedings, 1996.

Fraza, 1998 - V. Fraza, Streamlining the channel, Industrial Distribution 87 (9) (1998), pp. 73-74.

Fry et al., 2001 - M. J. Fry, R. Kapuscinski and T. L. Olsen, Coordinating production and delivery under a $(z, Z)$-type vendor managed inventory contract, Manufacturing \& Service Operations Management 3 (2) (2001), pp. 151-173.

Greasley and Barlow, 1998 - A. Greasley and S. Barlow, Using simulation modeling for BPR: resource allocation in a police custody process, International Journal of Operations and Production Management 18 (9/10) (1998), pp. 978-989.

Haavik, 2000 - S. Haavik, Building a demand-driven vendormanaged supply chain, Healthcare Financial Management 54 (2) (2000), pp. 56-61.

Harrell et al., 1996 - C. R. Harrell, R. E. Bateman, T. J. Gogg and J. R. A. Mott, System Improvement Using Simulation (fourth ed), PROMODEL Corporation, Orem (1996).

Hill, 2000 - T. J. Hill, Manufacturing Strategy: Text and Cases (third ed), Irwin McGraw-Hill, Boston (2000).

Holweg et al., 2005 - M. Holweg, S. M. Disney, J. Holmstrom and J. Smaros, Supply chain collaboration: Making sense of the strategy continuum, European Management Journal 23 (2) (2005), pp. 170-181.

Irani et al., 2000 - Z. Irani, V. Hlupic, L. P. Baldwin and P. E. D. Love, Re-engineering manufacturing processes through simulation modeling, Logistics Information Management 13 (1) (2000).

Jain, 1994 - C. L. Jain, Ready or not, here comes vendor-managed inventory, Journal of Business Forecasting Methods and Systems 13 (2) (1994), p. 2,44.

Jarugumilli and Grasman, 2007 - S. Jarugumilli and S. E. Grasman, RFID-enabled inventory routing problems, International Journal of Manufacturing Technology and Management 10 (1) (2007), pp. 92-105.

Kuk, 2004 - G. Kuk, Effectiveness of vendor-managed inventory in the electronics industry: Determinants and outcomes, Information \& Management 41 (2004), pp. 645-654.

Latamore, 1999 - G. B. Latamore, Customers, suppliers drawing closer through VMI, APICS - The Performance Advantage 12 (7) (1999), pp. 22-25.

Law and Kelton, 2000 - A. M. Law and W. D. Kelton, Simulation Modeling and Analysis (third ed), McGraw-Hill, Boston (2000).
Lawrence and Vokurka, 1999 - F. B. Lawrence and R. J. Vokurka, Two distributors, two approaches, APICS - The Performance Advantage 12 (7) (1999), pp. 26-29.

Lee and Elcan, 1996 - Y. Lee and A. Elcan, Simulation modeling for process engineering in the telecommunications industry, Interfaces 26 (3) (1996), pp. 1-9.

Levy and Dhruv, 2000 - M. Levy and G. Dhruv, Supply chain management in a networked economy, Journal of Retailing $\mathbf{7 6}$ (4) (2000), pp. 415-429.

Lo and Wee, 2005 - C.-C. Lo and H.-M. Wee, An effective integrated inventory model to coordinate inventory replenishment and shipment consolidation, Journal of Information $\mathcal{E} O p$ timization Sciences 26 (3) (2005), pp. 645-663.

Min and Zhou, 2002 - H. Min and G. Zhou, Supply chain modeling: Past, present and future, Computers $\mathcal{E}$ Industrial Engineering 43 (2002), pp. 231-249.

Mishra and Raghunathan, 2004 - B. K. Mishra and S. Raghunathan, Retailer- vs. vendor-managed inventory and brand competition, Management Science 50 (4) (2004), pp. 445-457.

Nachiappan et al., 2007 - S. P. Nachiappan, A. Gunasekaran and N. Jawahar, Knowledge management system for operating parameters in two-echelon VMI supply chains, International Journal of Production Research 45 (11) (2007), pp. 2479-2505.

Peapod LLC, 2008 - Peapod LLC, 2008. Peapod online grocery shopping and delivery service; $w w w$. peapod. com

Pohlen and Goldsby, 2003 - T. L. Pohlen and T. J. Goldsby, VMI and SMI programs: How economic value added can help sell the change, International Journal of Physical Distribution $\mathcal{E}$ Logistics Management 33 (7) (2003), pp. 565-581.

Spethman, 1993 - B. Spethman, Quaker gets a lock on its stock, Brandweek 34 (46) (1993), p. 3.

Tan et al., 2007 - T. Tan, R. Gullu and N. Erkip, Modeling imperfect advance demand information and analysis of optimal inventory policies, European Journal of Operational Research 177 (2007), pp. 897-923.

Vigtil, 2007 - A. Vigtil, Information exchange in vendor managed inventory, International Journal of Physical Distribution $\mathcal{E}$ Logistics Management 37 (2) (2007), pp. 131-147.

Waller et al., 1999 - M. Waller, M. E. Johnson and T. Davis, Vendor-managed inventory in the retail supply chain, Journal of Business Logistics 20 (1) (1999), pp. 183-203.

White and Censlive, 2006 - A. S. White and M. Censlive, Observations on modeling strategies for vendor-managed inventory, Journal of Manufacturing Technology and Management 17 (4) (2006), pp. 496-512.

Williams, 2000 - M. K. Williams, Making consignment- and vendor-managed inventory work for you, Hospital Material Management Quarterly 52 (4) (2000), pp. 59-63.

Yang et al., 2003 - K.-K. Yang, R. A. Rubin and S. Webster, Managing vendor inventory in a dual level distribution system, Journal of Business Logistics 24 (2) (2003), pp. 91-108.

Yao et al., 2007 - Y. Yao, P. T. Evers and M. E. Dresner, Supply chain integration in vendor-managed inventory, Decision Support Systems 43 (2007), pp. 663-674. 